\title{
PENDEKATAN JINSHIN NO HANA DALAM IMPLEMENTASI FESTIVAL ONLINE DI KECAMATAN DELANGGU
}

\author{
Pandu Purwandaru ${ }^{1}$, Kusumaningdiyah N.H. ${ }^{2}$, Novia Nur Kartikasari ${ }^{3}$, Gani Cahyo Handoyo ${ }^{4}$ \\ ${ }^{1}$ Desain Interior, Fakultas Seni Rupa dan Desain, Universitas Sebelas Maret \\ ${ }^{2}$ Teknik Arsitektur, Fakultas Teknik, Universitas Sebelas Maret \\ ${ }^{3}$ Seni Murni, Fakultas Seni Rupa dan Desain, Universitas Sebelas Maret \\ ${ }^{4}$ Agroteknologi, Fakultas Pertanian, Universitas Sebelas Maret \\ pandupurwandaru@staff.uns.ac.id ${ }^{1}$, kusumaningdyah_nh@staff.uns.ac.id², \\ novianurkartikasari@staff.uns.ac.id ${ }^{3}$, ganicahyo@staff.uns.ac.id ${ }^{4}$
}

\begin{abstract}
Abstrak
Kecamatan Delanggu adalah salah satu area di Kabupaten Klaten yang memiliki popularitas secara nasional dalam hal pertanian padi. Namun sangat disayangkan saat ini kekayaan yang terbangun dari kegiatan pertanian padi seperti budaya, alam dan elemen lainnya makin terkikis dengan arus perkembangan zaman. Oleh karena itu pendekatan edukasi perlu dilakukan kepada masyarakat lokal agar kembali memahami potensi yang mereka miliki dan menjadikannya elemen pembangun masyarakat yang berkelanjutan. Festival merupakan salah satu wadah yang bisa memberikan edutainment bagi masyarakat lokal. Melalui pendekatan Jinshin no Hana, festival dikembangkan dengan menekankan masyarakat lokal sebagai "pemeran utamanya". Dalam implementasinya pendekatan ini dilakukan dengan metode analisa "treasures mapping", stakeholders, brainstorming ide dan pemeringkatan melalui pairwise method, dan realisasi. Dalam implementasinya, kondisi pandemik membuat pendekatan diprioritaskan melalui online dan penyelenggaraannya secara terbatas di lapangan. Kegiatan yang dilakukan dalam festival ini ada 6 kategori, yaitu preservasi, perbaikan lingkungan, kesenian, publikasi UKM, permainan berbasis potensi lokal, dan workshop kerajinan jerami padi.
\end{abstract}

Kata Kunci: desa, festival, komunitas, online

\begin{abstract}
Delanggu District is one area in Klaten Regency that has national popularity in the rice farming sector. Unfortunately, in modern days, the intangible wealth developed from traditional rice farming activities such as culture, nature, and other elements are gradually disappeared. Therefore through educational approaches, it is essential to re-introduce the local community to increase their awareness of the local potential and create it as an element of sustainable community development. Festival is one of the media that can provide an edutainment approach for the local community. Through the use of the Jinshin no Hana method, the festival was developed by emphasizing the local community as the "main actor". In its implementation, this method is performed through treasure mapping analysis, stakeholders analysis, idea brainstorming, and ranking via the pairwise method and implementation. In this pandemic situation, the realization was prioritized by an online and limited person in field implementation. Activities performed in this festival divided into 6, (1) preservations, (2) environmental improvement, (3) art performances, (4) SME's publication, (5) games based on natural materials development, and (6) rice straw crafts workshops.
\end{abstract}

Keywords: community, festival, online, village 


\section{PENDAHULUAN}

Festival adalah suatu acara yang biasanya dirayakan oleh komunitas dan berpusat pada beberapa aspek karakteristik komunitas itu seperti budaya, infrastruktur dan juga alamnya. Di area Kecamatan Delanggu, secara tradisional festival hadir melalui ritual wiwitan yang diselenggarakan pada sore hari, sehari sebelum waktu panen padi. Dalam ritual itu kegiatan perayaan dilakukan dengan membuat sego wiwitan yang menjadi daya tarik bagi anak-anak untuk terlibat dalam kegiatan tersebut. Kegiatan selebrasi tersebut mengandung nilai-nilai seperti gotong- royong, edukasi, mitologi, dan juga lingkungan. Namun sangat disayangkan di desa Sabrang Kecamatan Delanggu, berdasarkan informasi dari ketua rukun tani, kegiatan ritual wiwitan sudah tidak pernah diselenggarakan lagi sejak 30 tahun lalu.

Kecamatan Delanggu memiliki posisi geografis yang strategis yaitu berlokasi dekat, sekitar $16 \mathrm{~km}$ dengan kota Surakarta, dan secara historis telah menjadi tulang punggung pangan dalam memasok beras berkualitas bagi Kasunanan Surakarta. Dengan dukungan "treasures" budaya dan stakeholders, Kecamatan Delanggu dipandang sangat potensial untuk penyelenggaraan festival.



Gambar 1. Lokasi dan area pertanian di Kecamatan Delanggu

[Sumber: Data penulis]

Dalam kondisi pandemik Covid-19 yang dihadapi secara global termasuk Indonesia, format penyelenggaraan kegiatan yang sifatnya mengumpulkan massa memiliki skema yang berbeda. Dalam Keputusan Menteri Kesehatan Nomor HK.01.07/MENKES/382/2020 tentang protokol kesehatan dikemukakan bahwa kegiatan seperti festival umum bisa saja diselenggarakan dengan beberapa syarat seperti (1) penyediaan fasilitas pengecekan, pembersihan, dan kesehatan, (2) pengaturan massa agar selalu menjaga jarak dan menggunakan masker, (3) membatasi pengunjung, (4) mengatur layout (kursi, meja, dan booth) dengan jarak minimal 1 meter, (5) memberikan informasi kepada calon pengunjung dengan informasi peraturan melalui media sosial, dan beberapa peraturan lainnya.

Dengan bertitik tolak dari peraturan tersebut, telah digagas untuk menyelenggarakan festival massal dengan melakukan pembatasan pengunjung, dengan pembagian waktu kunjungan berdasarkan kloter undangan disertai dengan protokol kesehatan lainnya. Namun melihat kondisi kedisiplinan masyarakat di tempat publik saat menghadapi 
pandemik serta hasil diskusi dengan masyarakat lokal, penyelenggaraan kegiatan dengan skema festival massal terbatas itu masih dianggap sangat beresiko. Oleh karena itu, sebagai opsi yang dianggap paling potensial, festival online menjadi pilihan penyelenggaraan di Kecamatan Delanggu karena juga mayoritas masyarakatnya sudah tersambung dengan akses internet melalui smartphone.

Di tengah pandemik, kegiatan festival tetap dibutuhkan sebagai wadah edutainment bagi masyarakat lokal. Dalam kegiatan ini, pendekatan dalam penyelenggaraan dilakukan dengan metode Jinshin no Hana/人心の花 atau Flowering of the Total Person, yaitu dengan memposisikan masyarakat lokal sebagai aktor utama serta melakukan pengembangan dengan berbasis kepada local treasures dan stakeholders. Tujuan yang hendak dicapai yaitu menghasilkan pengembangan wilayah lokal yang berkelanjutan, dengan outputnya yaitu menghasilkan formulasi turisme dan pengembangan kerajinan tangan dari suatu wilayah lokal.

\section{METODE PENELITIAN}

Dalam penyelenggaraan kegiatan digunakan metode pengembangan budaya dalam suatu komunitas, yaitu (1) dengan murni preservasi dan/atau (2) pengembangan. Kedua pendekatan tersebut penting dalam hal melestarikan keautentikan dan juga mengembangkannya sehingga dapat diterima oleh masyarakat sesuai dengan perkembangan jaman. Metode Jinshin no Hana digunakan dengan menekankan masyarakat lokal sebagai "aktor utamanya". Metode ini diperkenalkan pertama kali oleh Profesor Kiyoshi Miyazaki dari laboratorium Design Culture, Chiba University, Jepang. Inti dari metode ini yaitu bagaimana tim desainer dapat merancang "Designing Living" yaitu menghidupkan masyarakat melalui pendekatan "what should be" atau apa yang seharusnya dilakukan dari potensi lokal yang ada.

Pada tahap awal tim mahasiswa dan dosen melakukan survei langsung ke lapangan dengan melakukan pemetaan "treasures" atau potensi, baik yang tangible maupun intangible. Proses ini dilakukan dengan memposisikan masyarakat lokal sebagai guru. Dalam proses ini juga dilakukan stakeholders mapping untuk memetakan kelompokkelompok lokal yang ada di desa dalam mendukung kegiatan festival. Dalam proses desain kegiatan festival, beberapa potensi kegiatan di-list lalu didiskusikan potensi penyelenggaraannya dengan menggunakan metode pairwise ranking untuk mengetahui prioritas implementasi idenya. Penyelenggaraan dilakukan dengan secara terbatas dan memprioritaskan pembuatan dokumentasi untuk didiseminasikan kepada masyarakat lokal melalui festival online.

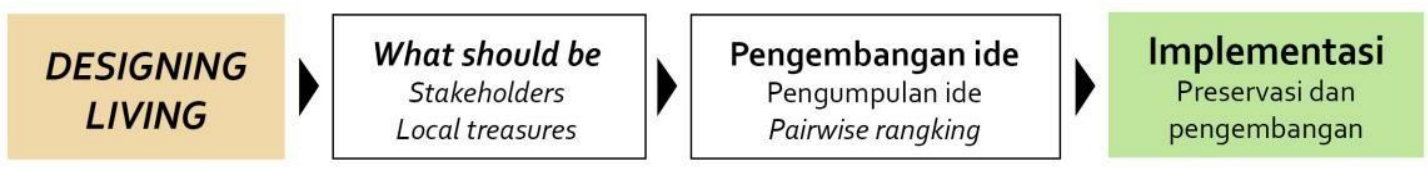

Gambar 2. Metode penelitian implementasi Jinshin no Hana

[Sumber: Data penulis] 


\section{HASIL DAN PEMBAHASAN}

Hasil dan pembahasan dari pelaksanaan perancangan festival online berbasis pendekatan Jinshin no Hana dibagi atas lima kegiatan utama dari perancangan hingga proses diseminasi dengan penjabaran sebagai berikut:

\subsection{Treasures Mapping}

Dari hasil treasures mapping terhadap elemen tangible dan intangible, ditemukan berbagai potensi menarik seperti ritual, potensi alam, pemandangan, kebudayaan, kerajinan dan kesenian yang secara mayoritas berpusat pada lingkup pertanian padi. Dalam proses pemetaan potensi, visualisasi dibuat oleh tim dari mahasiswa sehingga proses diskusi menjadi menarik. Dalam konteks tangible object, banyak potensi yang sudah terkikis oleh arus modernisasi seperti beberapa area persawahan yang beralih fungsi menjadi kawasan properti, sementara dalam konteks intangible saat ini sudah banyak keahlian-keahlian dalam membuat kerajinan seperti gubuk jerami, tali waru, dan lainnya serta prosesi ritual yang sudah ditinggalkan oleh petani sehingga penting untuk segera dilakukan kegiatan pelestarian.

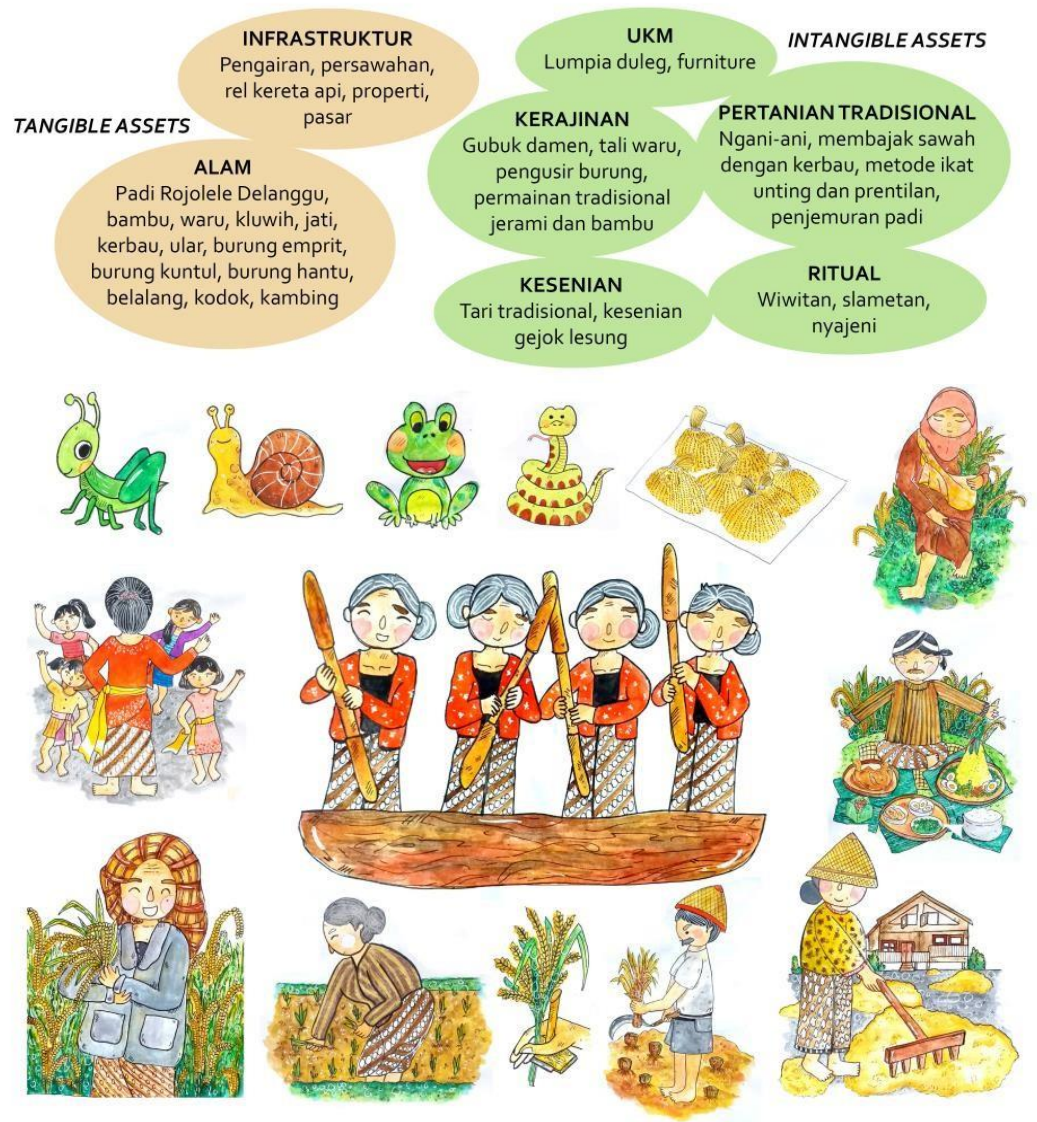

Gambar 3. Treasures mapping Kecamatan Delanggu

[Sumber: Data penulis] 


\subsection{Analisis Stakeholders}

Dari hasil analisis stakeholders yang dilakukan oleh tim mahasiswa dan dosen, maka dapat dipetakan bahwa terdapat 6 elemen internal yang potensial untuk dijadikan "aktor utama" dalam penyelenggaraan festival ini, yaitu (1) pemerintah yaitu kelurahan, (2) organisasi pertanian yaitu kelompok tani Sedyo Makmur, (3) institusi pendidikan, yaitu TK Al-Hikam dan SMK Muhammadiyah Delanggu, (4) organisasi internal desa, yaitu ibu-ibu PKK dan Karang Taruna, (5) UKM, yaitu sentra lumpia duleg, dan (6) sanggar kesenian lokal, yaitu sanggar seni Semoyo Endo.

Dari potensi stakeholders tersebut, dapat dipetakan berdasarkan kegiatannya yaitu untuk kegiatan preservasi dan perbaikan lingkungan pertanian oleh organisasi pertanian, kegiatan kreatif berbasis potensi desa dilakukan dengan institusi pendidikan dan ibu-ibu PKK, kegiatan pentas kesenian oleh sanggar seni lokal, dan upaya mempopulerkan potensi ekonomi lokal dengan mitra UKM. Tim dari FSRD UNS dalam kegiatan ini diposisikan sebagai elemen stakeholders eksternal yang bertugas memfasilitasi serta mengusulkan ide dengan pertimbangan "treasures" dan stakeholders lokal. Dalam pelaksanaannya, dikarenakan kondisi pandemik, terdapat beberapa stakeholders belum bisa secara aktif berpartisipasi dalam kegiatan perancangan festival online.

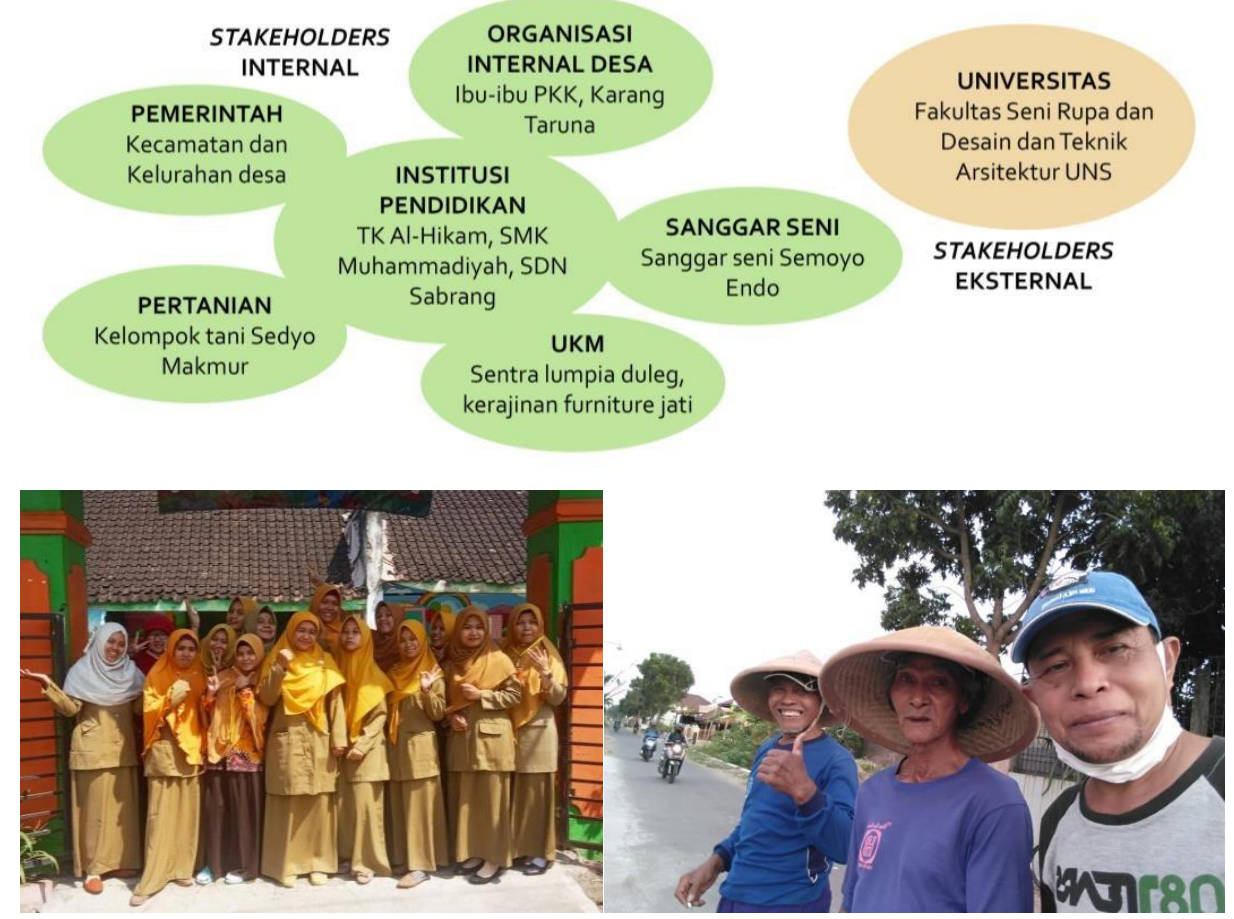

Gambar 4. Analisa stakeholders Kecamatan Delanggu

[Sumber: Data penulis]

\subsection{Pairwise Ranking}

Setelah terbentuk tim dari unsur stakeholders, dilakukan diskusi untuk mengumpulkan Ide-ide berkaitan dengan penyelenggaraan festival. Ide-ide tersebut ditentukan berdasarkan tujuan dari festival antara lain, preservasi, kreatifitas, partisipasi, dan 
publikasi. Terdapat 12 ide utama yang bisa dikembangkan dan perlu untuk diketahui lebih lanjut ide manakah yang menjadi prioritas untuk ditindaklanjuti. Dalam hal ini, metode pairwise ranking digunakan dengan cara membuat tabel dan membuat komparasi antara satu ide dengan yang lainnya berdasarkan variabel penentu keamanan pelaksanaan pada masa pandemik dan tingkat ketercapaian dalam tujuan festival.

Tabel 1. Pairwise ranking dari rencana penyelenggaraan festival Ngani-ani [Sumber: Data penulis]

\begin{tabular}{|l|l|l|l|l|l|l|l|l|l|l|l|l|l|l|l|}
\hline No & \multicolumn{1}{|c|}{ KEGIATAN } & (A) & (B) & (C) & (D) & (E) & (F) & (G) & (H) & (I) & (J) & (K) & (L) & Nilai & Ranking \\
\hline 1 & Festival terbatas (A) pertanian & 0 & - & 1 & 1 & 1 & 1 & 1 & 1 & 1 & 1 & 1 & 1 & 10 & 1 \\
\hline 2 & $\begin{array}{l}\text { Dokumentasi pelestarian } \\
\text { tradisional (B) }\end{array}$ & & & & & & & & & & & \\
\hline 3 & $\begin{array}{l}\text { Pelestarian varietas Rojolele Delanggu } \\
\text { (C) }\end{array}$ & & 1 & - & 1 & 0 & 1 & 1 & 1 & 1 & 1 & 1 & 1 & 9 & 2 \\
\hline 4 & $\begin{array}{l}\text { Pemanfaatan limbah jerami dan } \\
\text { gerabah untuk kerajinan (D) }\end{array}$ & 0 & 1 & 1 & - & 0 & 1 & 1 & 1 & 0 & 1 & 1 & 1 & 8 & 4 \\
\hline 5 & Kegiatan perbaikan lingkungan (E) & 0 & 1 & 0 & 0 & - & 1 & 1 & 1 & 1 & 1 & 1 & 1 & 8 & 5 \\
\hline 6 & Dokumentasi tari tradisional Gatak (F) & 0 & 1 & 1 & 1 & 1 & - & 0 & 1 & 0 & 0 & 0 & 1 & 6 & 9 \\
\hline 7 & Dokumentasi potensi UKM (G) & 0 & 1 & 1 & 1 & 1 & 0 & - & 1 & 1 & 0 & 1 & 1 & 8 & 6 \\
\hline 8 & Mural desa (H) & 0 & 1 & 1 & 1 & 1 & 1 & 1 & - & 1 & 0 & 1 & 1 & 9 & 3 \\
\hline 9 & Pelestarian kerajinan tradisional (I) & 0 & 1 & 1 & 0 & 1 & 0 & 1 & 1 & - & 0 & 0 & 1 & 6 & 8 \\
\hline 10 & Mainan anak-anak berbasis alam (J) & 0 & 1 & 1 & 1 & 1 & 0 & 0 & 0 & 0 & - & 0 & 1 & 5 & 10 \\
\hline 11 & Infrastruktur festival (K) & 0 & 1 & 1 & 1 & 1 & 0 & 1 & 1 & 0 & 0 & - & 1 & 7 & 7 \\
\hline 12 & Dokumentasi tari dari SMK Delanggu (L) & 0 & 0 & 0 & 0 & 0 & 0 & 0 & 0 & 0 & 0 & 0 & - & 0 & 12 \\
\hline
\end{tabular}

Dari hasil analisis pairwise ranking, pelestarian budaya pertanian padi tradisional adalah hal yang paling mendesak untuk diselenggarakan melalui festival karena kondisi yang sudah akan punah begitupula pelestarian varietas lokal Rojolele yang saat ini memang sudah tidak ada lagi yang menanam di Kecamatan Delanggu. Kegiatan preservasi tersebut diikuti dengan kegiatan kreatif seperti mural, pengembangan kerajinan jerami, perbaikan lingkungan, pentas seni, pendokumentasian potensi UKM, dan permainan berbasis material alam. Beberapa kegiatan merupakan peringkat terendah dan tidak menjadi prioritas untuk diselenggarakan dalam kondisi saat ini yaitu penyelenggaraan festival masal dengan metode terbatas per waktu, dan kegiatan seni tari yang dilakukan oleh SMK Muhammadiyah dikarenakan belum diterapkannya pendekatan luring di sekolah.

\subsection{Penyelenggaraan Festival}

Penyelenggaraan pembuatan festival daring diselenggarakan dari awal Agustus 2020 hingga pertengahan Oktober 2020 di Desa Sabrang dan Desa Gatak Kecamatan Delanggu. Dari hasil diskusi bersama warga lokal, festival ini disepakati untuk bernama "Festival Ngani-ani" yaitu berasal dari istilah metode panen tradisional dengan menggunakan alat ani-ani. Dalam kegiatan ngani-ani terdapat beberapa nilai yang diimplementasikan oleh petani tradisional, seperti kesabaran, kebahagiaan, hormat kepada alam, dan keterampilan yang keseluruhan nilai tersebut selaras dengan kegiatan 
festival yang diselenggarakan. Logo yang dibuat untuk kegiatan festival ini juga merepresentasikan representasi dari pertanian padi, unsur budaya dan juga representasi dari ikon-ikon karya kerajinan tradisional.

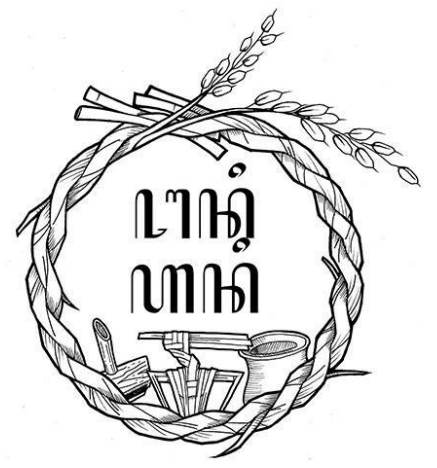

Gambar 5. Logo Festival Ngani-ani Kecamatan Delanggu

[Sumber: Data penulis]

Dalam pelaksanaannya, berdasarkan dari bagan alir penelitian, output utama dari festival yaitu dokumentasi. Secara rinci dalam kegiatan pendokumentasiannya terdapat beberapa pendekatan, yaitu dengan melakukan perekaman yang sifatnya kegiatan pelestarian, permainan, kesenian, perbaikan lingkungan dan publikasi UKM dengan mengumpulkan beberapa kelompok stakeholders secara terbatas, serta pembuatan tutorial berkaitan dengan artefak tradisional dan pengembangannya.

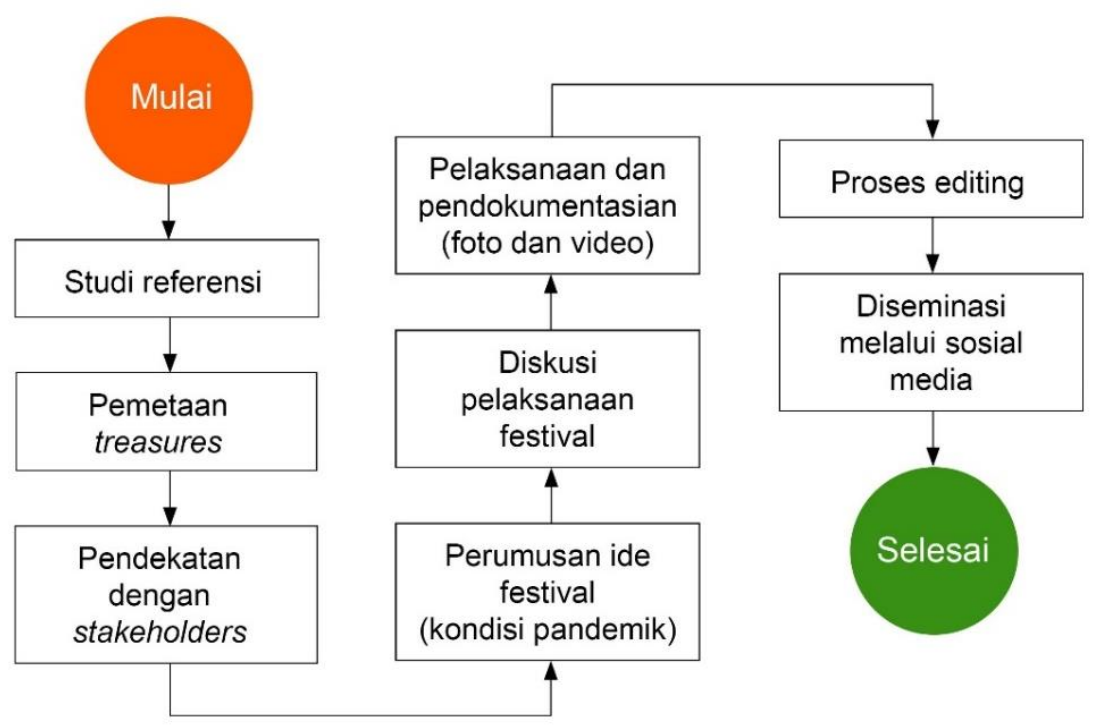

Gambar 6. Bagan Alir Penelitian

[Sumber: Data penulis]

\section{a. Kegiatan pelestarian}

Terdapat 6 kegiatan preservasi dalam festival Ngani-ani, secara keseluruhan menurut stakeholders lokal sangat mendesak untuk dilakukan sebagai upaya pendokumentasian budaya tersebut sebelum punah, yang secara keseluruhan di lingkup pertanian padi tradisional. Yang pertama adalah pembuatan arsitektural vernakular gubuk damen yang 
saat ini di Kecamatan Delanggu sudah tidak ditemukan lagi di wilayah pertanian. Dalam pembuatan gubuk ini, petani yang memiliki keahlian dalam pembuatan gubuk memimpin para petani lainnya dalam pembangunannya. Secara autentik, material yang digunakan adalah bambu pada bagian rangka, dan jerami padi pada bagian atap, yang secara keseluruhan didapat dari area pertanian dan sekitarnya. Kedua adalah pembuatan tali waru yang merupakan tali tradisional yang saat ini sudah hampir tidak ditemukan lagi digunakan di area Kecamatan Delanggu. Di masa lalu, tali ini sangatlah luas penggunaannya dari pengikat rangka arsitektural hingga pengikat kemasan, dan tergolong tali yang kuat selain tali bambu. Cara pembuatannya pun sangat berkaitan dengan dunia pertanian padi yaitu dengan perendaman di lumpur persawahan sebagai proses pemisahan kulit halus dari kulit keras dari pohon waru.
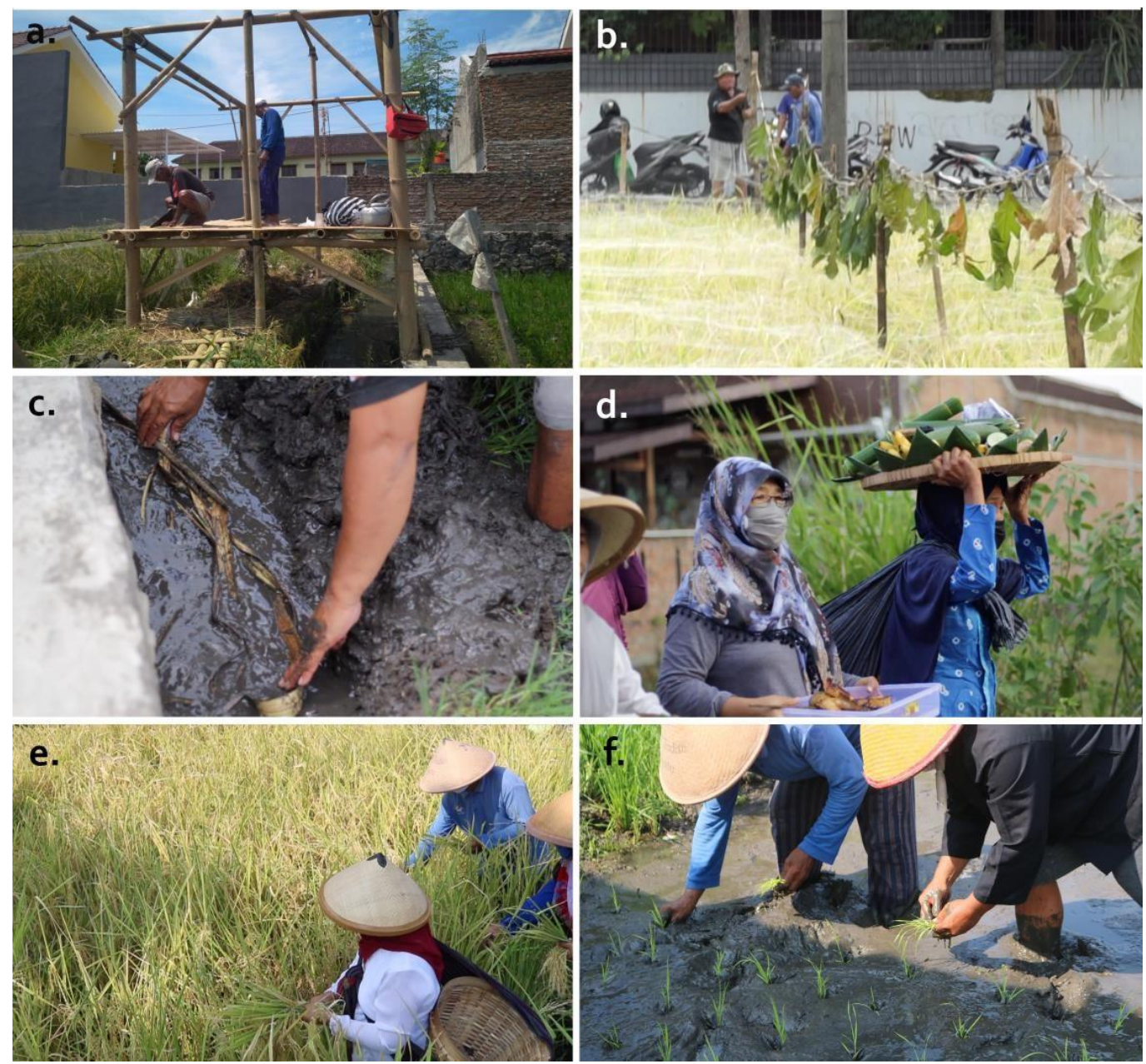

Gambar 7. Kegiatan preservasi, a. pembuatan gubuk damen, b. tali pengusir burung, c. pembuatan tali waru, d. ritual wiwitan, e. pelaksanaan ngani-ani, f. penanaman kembali padi Rojolele Delanggu

[Sumber: Data penulis]

Ketiga yaitu pembuatan alat pengusir burung tradisional yang menggunakan tali waru yang diikatkan dengan daun kluwih yang berdimensi lebar. Tali tersebut diikatkan memanjang di area persawahan dengan pengontrolan dilakukan dari gubuk damen dengan menggoyang-goyangkan tali ketika burung datang. Keempat yaitu pelaksanaan ritual wiwitan atau ritual pra-panen yang selama sekitar 30 tahun secara masal sudah 
tidak diselenggarakan lagi di area pertanian desa Sabrang. Oleh karena itu ritual diselenggarakan kembali dengan partisipasi kelompok tani dan anak-anak desa secara terbatas. Di hari selanjutnya yaitu pelaksanaan panen tradisional dengan alat ani-ani (ngani-ani), pelaksanaan kegiatan ini dilakukan oleh ibu-ibu yang masih terampil dalam menggunakan alat tersebut dan juga secara tradisional di masa lalu panen hanya boleh dilakukan oleh perempuan karena padi dianggap sebagai representasi Dewi Sri.

Kegiatan terakhir yaitu pelestarian varietas padi Rojolele Delanggu asli. Di Kecamatan Delanggu secara nasional dikenal akan padi Rojolelenya, namun ironisnya saat ini tidak ada petani yang menanam varietas tersebut dikarenakan masa tanamnya yang lama. Di sisi lain, secara historis padi tersebut memiliki nilai budaya yang sangat kuat dengan kehidupan masyarakat tradisional. Oleh karena itu didukung oleh Balai Besar Penelitian Tanaman Padi Subang, benih Rojolele Delanggu asli dibudidayakan kembali dengan tujuan selebrasi ketika panen nanti untuk memperkenalkan potensi lokal tersebut kepada masyarakat.

\section{b. Kegiatan perbaikan lingkungan}

Pengairan yang baik adalah kunci dari keberhasilan pertanian. Dengan kualitas air yang baik maka akan menghasilkan kualitas padi yang baik juga. Oleh karena itu mengadaptasi penelitian dari Kondo Yuichiro dan Kimihide Nagase dari Chiba University, ecofish dibuat di area persawahan desa Sabrang dengan partisipasi kelompok tani Sedyo Makmur. Ecofish adalah jerami yang dibentuk menyerupai ikan dan diisi dengan hasil bakaran sekam padi dan bertujuan untuk menyerap kotoran dalam saluran air. Kegiatan ini didukung langsung oleh salah satu desainer dari ecofish yaitu Kimihide Nagase, dan sebanyak 40 karya yang dibuat petani diletakkan di saluran irigasi yang ditentukan oleh ketua rukun tani sebagai sampel lokasinya. Melalui kegiatan ini setiap ecofish dapat menyerap kotoran hingga 2,4 kali berat abu sekam di dalam ecofish.



Gambar 8. Pembakaran sekam dan instalasi ecofish di saluran irigasi persawahan

[Sumber: Data penulis]

\section{c. Kegiatan kesenian}

Kegiatan pentas seni dilakukan secara terbatas dan memfokuskan pada pendokumentasian untuk kegiatan festival online. Pentas seni diselenggarakan oleh sanggar seni Semoyo Endo Desa Gatak Kecamatan Delanggu dengan mementaskan 3 kesenian antara lain (1) tarian lumpia duleg yang gerakannya terinsipirasi dari cara 
membuat jajanan tradisional, (2) tarian dan nyanyian gundul-gundul pacul dan padang bulan yang merupakan lagu-lagu tradisional karya komposer karawitan Jawa RC Hardjasoebrata, dan (3) kesenian lesung jumengglung yang merupakan permainan musik khas petani ketika menumbuk padi dengan menggunakan alu yang dipukulkan ke lesung. Festival online ini menjadi wadah publikasi kesenian bagi sanggar seni lokal.

Kegiatan kesenian lainnya yaitu seni mural dengan menggambar karya di salah satu titik strategis di desa Sabrang. Ide dari mural diambil dari beberapa karya anak-anak TK Al-Hikam Delanggu dengan tema potensi desa Sabrang. Karya tersebut kemudian dibuat kolase oleh tim ahli gambar anak yang kemudian dikembangkan oleh tim dari mahasiswa Seni Murni FSRD UNS untuk diimplementasikan ke karya mural. Karya ini merupakan representasi kesenian berbasis partisipasi yang potensial untuk diselenggarakan dalam kondisi pandemik.

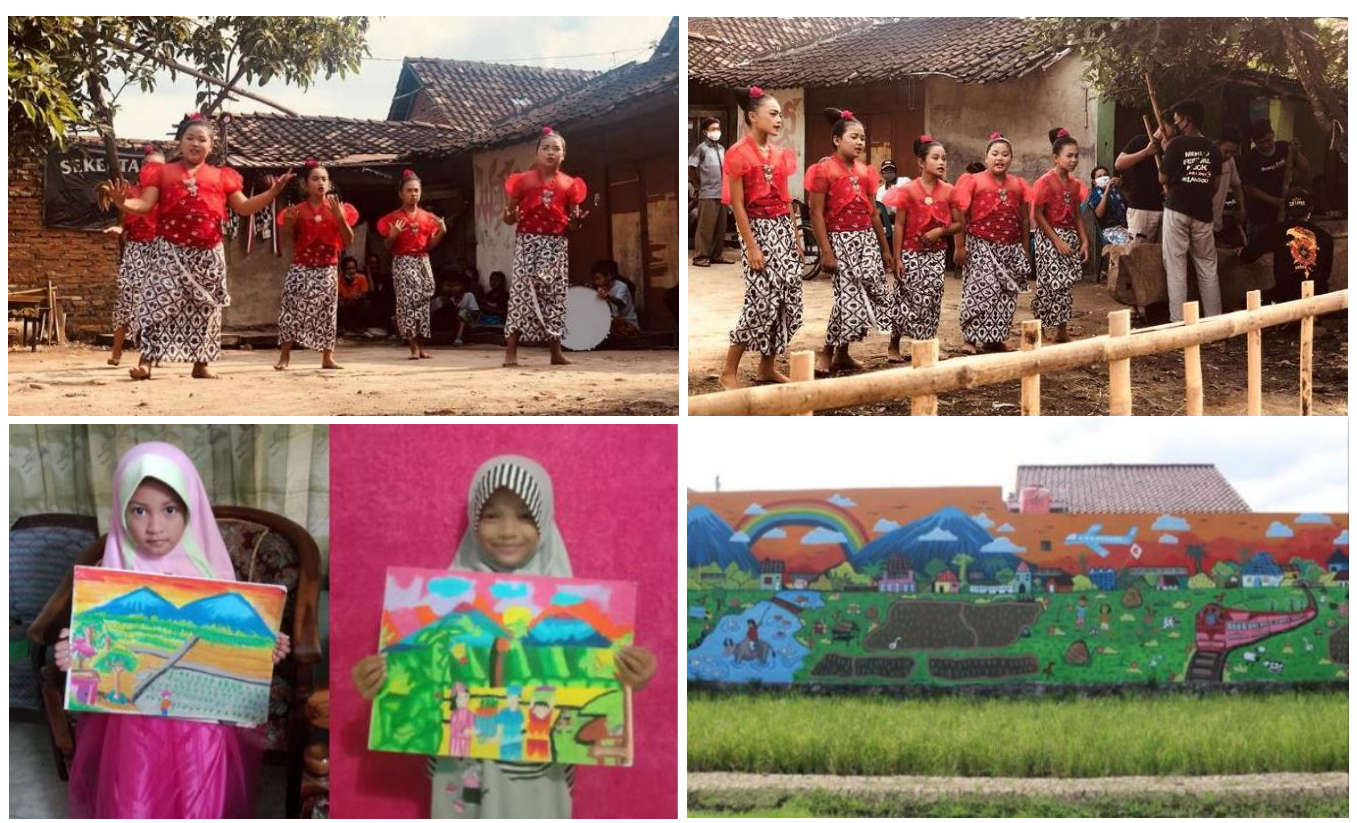

Gambar 9. Seni tari dan gejok lesung sanggar Semoyo Endo (atas) dan mural yang dikembangkan dari karya siswa-siswi TK Al-Hikam Delanggu

[Sumber: Data penulis]

\section{d. Kegiatan publikasi UKM}

Terdapat potensi UKM yang terletak di area Kecamatan Delanggu, salah satunya ada lumpia duleg. Proses pembuatan dari lumpia ini sangat sederhana yaitu diledre (mengolesi minyak di wajan dan memasak kulit lumpia), dilinting (memasukkan tauge ke dalam kulit lumpia), diungseng (memasak kembali dengan menggunakan sedikit minyak). Keunikan ini yang didokumentasi dan disebarluaskan melalui festival online, karena hingga saat ini belum semua masyarakat lokal di Kecamatan Delanggu mengenal jajanan tradisional ini secara mendalam. 


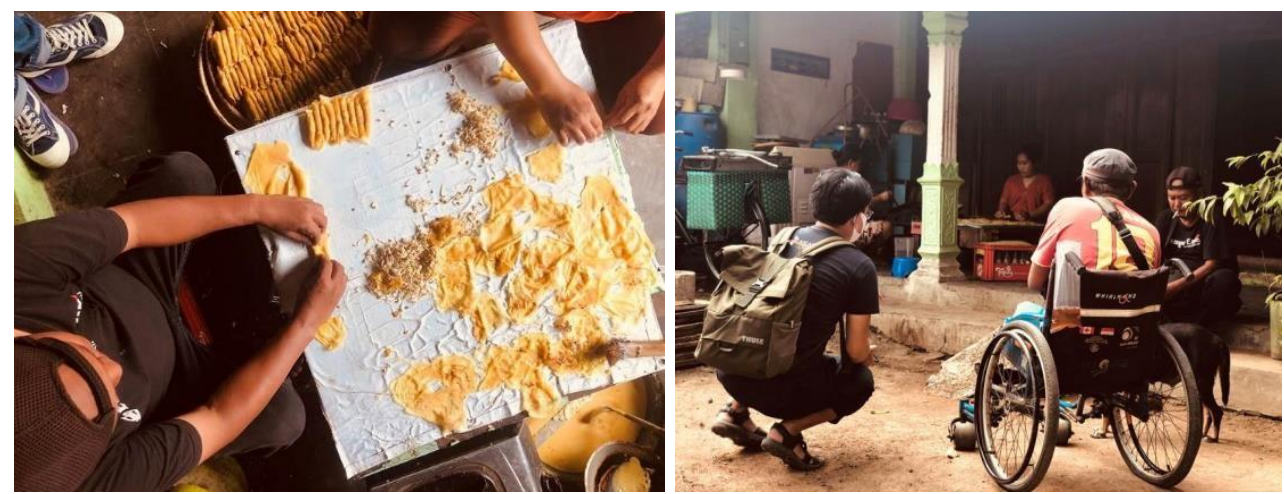

Gambar 10. Proses pendokumentasian sentra UKM lumpia duleg desa Gatak [Sumber: Data penulis]

\section{e. Permainan berbasis potensi lokal}

Kepekaan generasi muda di Kecamatan Delanggu terhadap lingkungan saat ini sangat rendah. Dikarenakan arus digitalisasi, skill keahlian tangan membuat alat (manusia sebagai homo faber), serta aspek motorik kasar dari generasi muda tersebut juga makin berkurang. Oleh karena itu, melalui festival ini material yang dianggap sebagai limbah oleh masyarakat yaitu jerami padi dan juga limbah gerabah dipergunakan untuk membuat mainan. Terdapat lima mainan yang diperkenalkan kepada anak-anak di desa Sabrang, yang pertama dolanan lempar damen, yaitu permainan melempar jerami yang dibentuk menjadi lingkaran dan memasukannya ke dalam tiang kayu atau bambu. Kedua adalah balap kebo damen yaitu mainan yang terinspirasi dari kerbau sebagai kawan anak-anak petani ketika menemani orangtuanya ke sawah di masa lalu. Kerbau dalam permainan ini dibuat dari jerami, dan diletakkan di atas arena balap yang terbuat dari karton lalu dikompetisikan dengan teman bermainnya.

Ketiga adalah puter bambu yaitu permainan dengan memegang tongkat bambu berdiameter kecil dan memutar-mutarkan lingkaran bambu sambil berjalan dan harus menjaga lingkaran bambu tersebut agar stabil di tengah-tengah batang bambu saat diputarkan. Keempat yaitu bermain dengan menggunakan pecahan limbah gerabah dan membuat mozaik karya. Kegiatan ini dilakukan secara berkelompok dan menggunakan material frame kayu dan cairan gypsum sebagai perekat dari pecahan gerabahnya. Beberapa bentukan diikuti oleh anak-anak dalam membuat mozaik, seperti ikan, bebek, rumah, dan lainnya. Keseluruhan mainan yang sudah disebutkan di atas dipraktekkan dengan partisipasi anak-anak di desa Sabrang di area TK Al-Hikam Delanggu.

Sementara dua permainan lainnya yaitu pembuatan tutorial anyaman kebo damen, dengan merekam video tahap demi tahap pembuatan kerajinan tangan tersebut. Yang terakhir adalah video tutorial dari pembuatan wayang damen Dewi Sri dan Raden Sadhono. Kerajinan pembuatan dolanan wayang damen pada dasarnya sudah dianggap punah oleh masyarakat Kecamatan Delanggu karena pengrajin terakhir yang bisa membuatnya sudah tidak ada. Oleh karena itu rekonstruksi artefak dilakukan melalui konfirmasi dengan masyarakat lokal dan tutorial pembuatannya dibuat melalui video dokumentasi. 

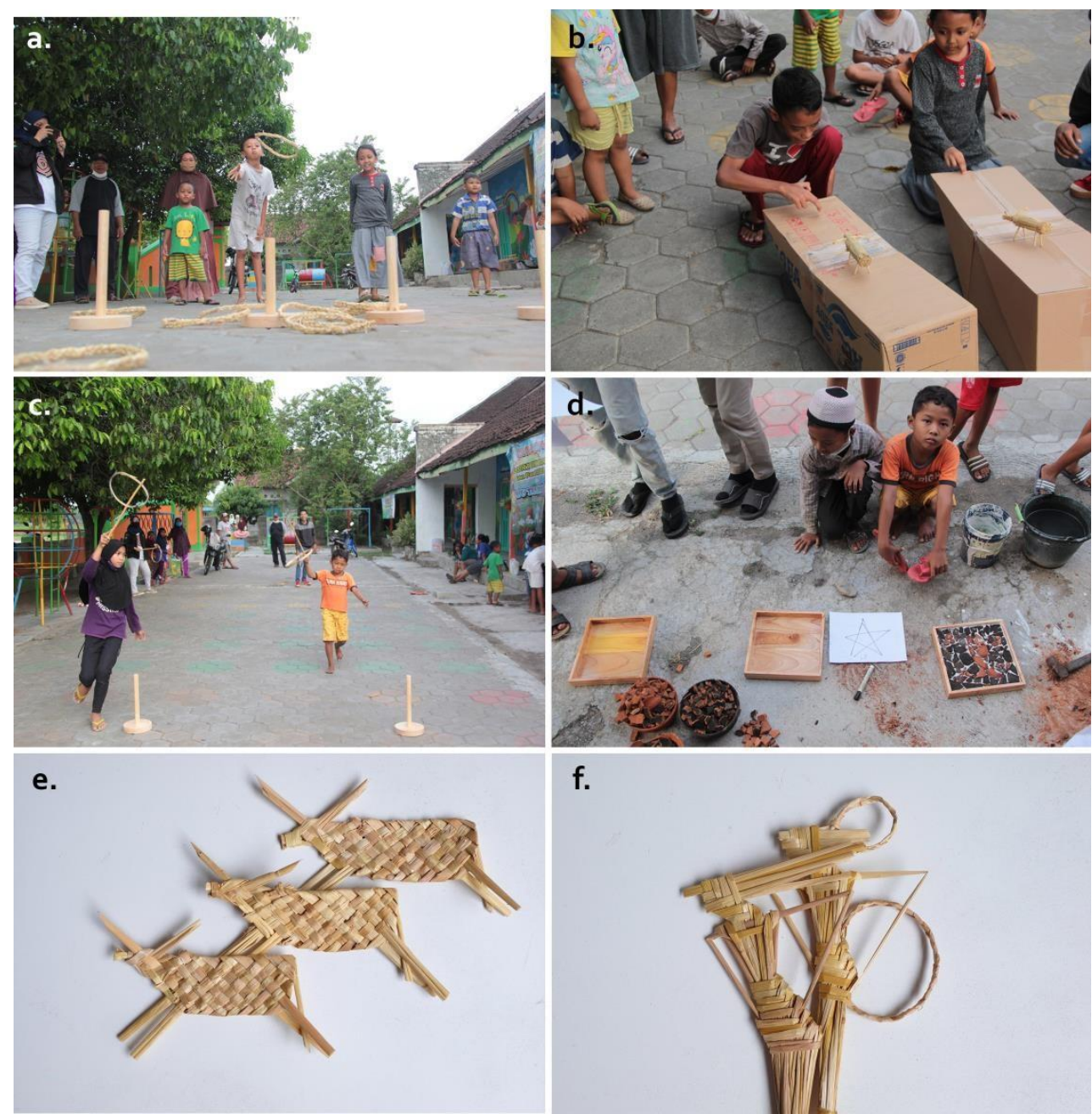

Gambar 11. Penyelenggaraan kegiatan dolanan, a. lempar damen, b. balap kebo damen, c. puter bambu, d. mozaik limbah gerabah, e. kebo damen anyam, dan f. wayang damen Sri Sadhono [Sumber: Data penulis]

\section{f. Pengembangan kerajinan tangan berbasis potensi lokal}

Jerami merupakan potensi paling berlimpah di Kecamatan Delanggu, melalui data Biro Pusat Statistik 2018 terdapat 20.395 ton beras yang diproduksi wilayah tersebut dan kuantitas jeraminya sebanyak sekitar 31.500 ton. Hingga saat ini masyarakat lokal masih menganggap jerami sebagai limbah yang tidak memiliki nilai ekonomi. Oleh karena itu kegiatan workshop dilakukan dalam festival ini bersama dengan ibu-ibu PKK desa Sabrang untuk memperkenalkan potensi dari material jerami untuk dijadikan kerajinan tangan. Beberapa metode diperkenalkan, khususnya yaitu proses persiapan dan pembuatan teknik coiling dalam membuat kerajinan jerami.

Kegiatan lainnya dalam menggali potensi lokal yaitu pembuatan banyu londo. Secara tradisional banyu londo adalah sabun tradisional yang terbuat dari campuran air dan bakaran merang dan digunakan untuk membersihkan tubuh. Saat ini sudah tidak ada lagi yang menggunakan sabun tradisional tersebut padahal secara lingkungan buangan dari sabun ini tidak memberikan dampak negatif sama sekali terhadap ekosistem alam. 
Dengan kegiatan festival pembuatan banyu londo diperkenalkan kembali kepada para ibu-ibu PKK disertai dengan workshop dalam pembuatan sikat damen-nya, sehingga mereka dapat menggunakannya untuk mencuci alat makan dan masak di dapur.

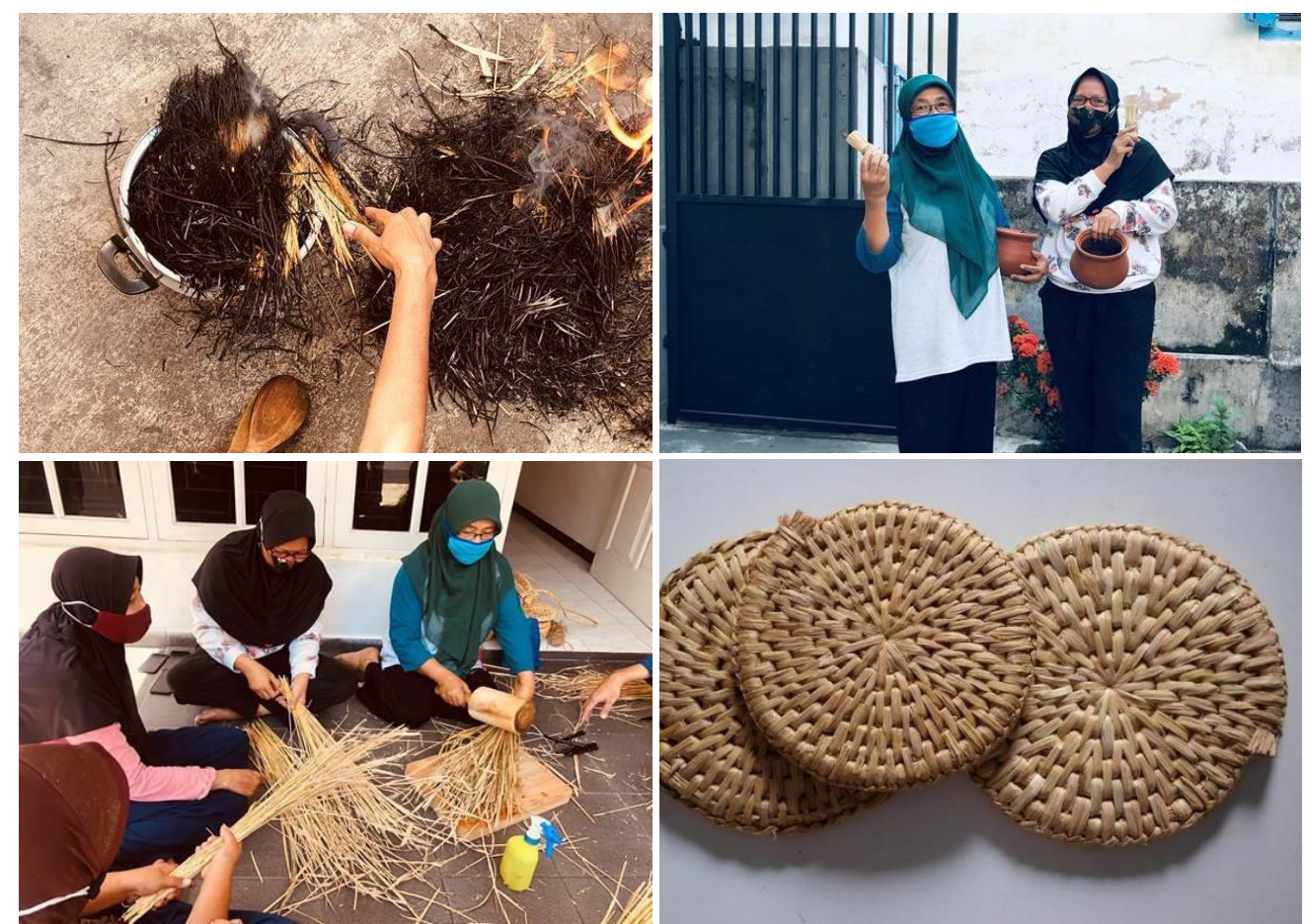

Gambar 12. Workshop pembuatan banyu londo dan sikat damen (atas), dan workshop pembuatan alas jerami dengan menggunakan teknik coiling bersama ibu-ibu PKK

[Sumber: Data penulis]

\subsection{Penyebaran Media}

Video dan foto adalah bahan digital utama dalam pembuatan materi diseminasi festival online kepada masyarakat. Untuk video, pengambilan gambar dilakukan dengan kamera dan juga drone untuk kegiatan outdoor. Masing-masing video diedit dengan menggunakan software adobe premiere dan after effect untuk animasi dan teksnya. Video diklasifikasikan berdasarkan kegiatannya seperti preservasi, tutorial, seni tari dan lainnya, dan di upload ke account nganiani festival. Berkaitan dengan foto, masingmasing kegiatan diupload ke laman Instagram @festivalnganiani dan Facebook nganiani festival. Untuk menunjang penyebaran informasi secara lokal, informasi laman sosial media dipublikasi di mural yang dibuat dalam kegiatan festival karena lokasinya yang strategis. Pendekatan ke stakeholders juga dilakukan untuk penyebarluasan festival dari mulut ke mulut. 


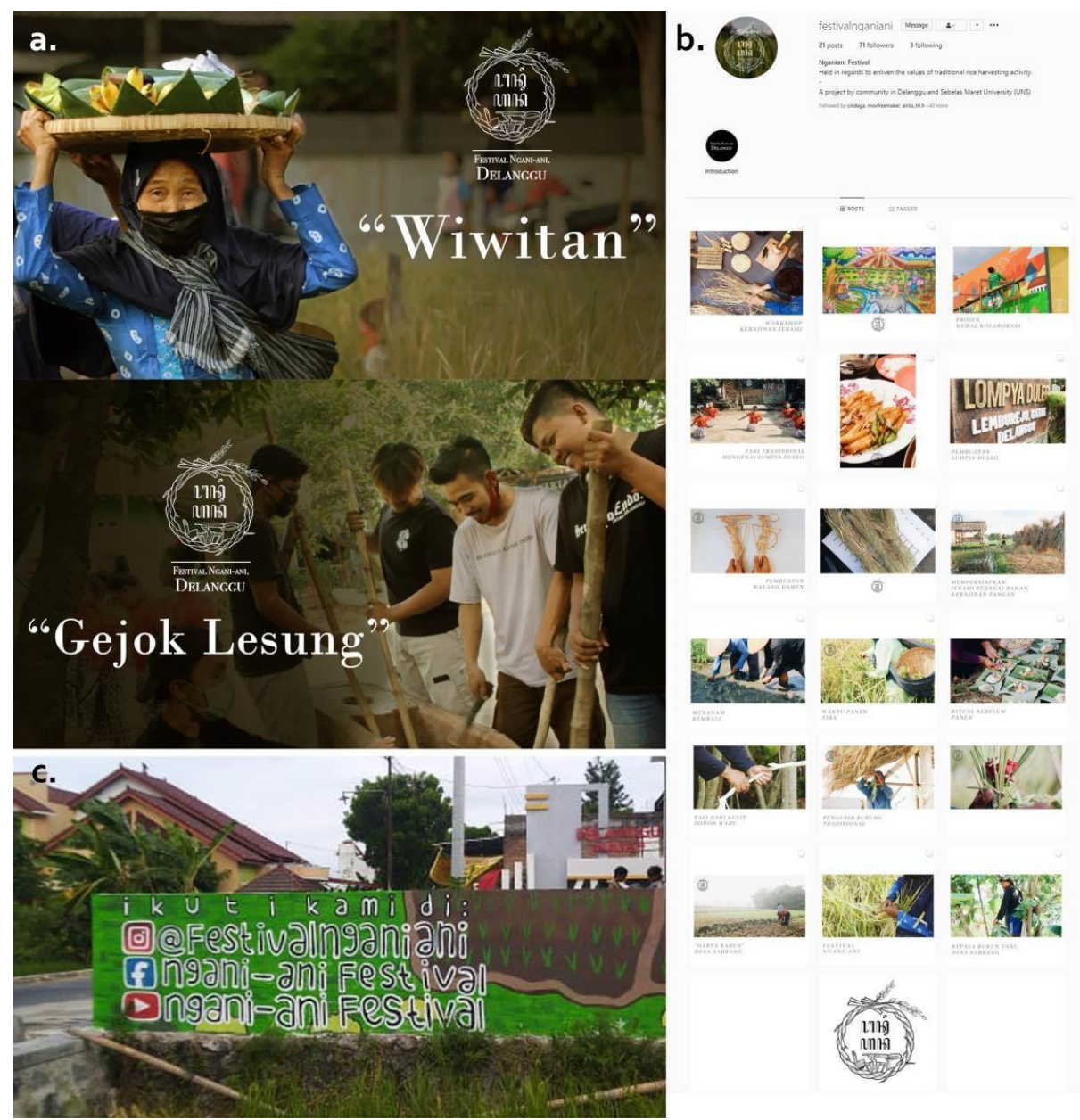

Gambar 13. Thumbnails beberapa video kegiatan festival di youtube (a), laman Instagram festival (b), dan publikasi festival melalui mural (c) [Sumber: Data penulis]

\section{KESIMPULAN}

Festival online tidak akan sepenuhnya dapat mengganti festival masal di desa dikarenakan hanya menggunakan pendekatan dua indera yaitu penglihatan dan pendengaran. Tetapi dalam situasi kondisional, festival online tetap dapat menjadi wadah bagi masyarakat lokal untuk selebrasi, dan dengan video tutorial, masyarakat juga dapat partisipasi dengan berkarya dengan material alam mengikuti video-video tutorial yang ada. Melalui pendekatan Jinshin no Hana, kegiatan ini tetap dapat menjadikan local stakeholders sebagai "pemeran utamanya". Pendekatan ini juga menekankan pada bagaimana masyarakat lokal dapat mewarisi kearifan lokal melalui berbagai kegiatan festival seperti preservasi dan pengembangan budaya dan potensi lokal.

Dari kegiatannya, festival online ini memberikan dampak kebahagiaan bagi masyarakat yang berpartisipasi, kebanggaan dari video yang dipublikasi mengenai potensi desa yang mereka miliki, serta wadah edukasi dan entertainment yang bisa diimplementasikan secara pribadi maupun kelompok di masa pandemik melalui video tutorial. Secara perlahan, kegiatan preservasi dari festival ini juga perlahan dapat memberikan 
pengaruh pada masyarakat lokal seperti mulainya kembali beberapa petani menyelenggarakan ritual wiwitan berskala kecil sebagai wujud syukur terhadap Tuhan, serta tingkat partisipasi petani dalam melestarikan padi lokal Rojolele. Festival online ini juga menjadi "teaser trailer" bagi masyarakat lokal serta umum untuk mempublikasikan kegiatan-kegiatan yang ada dalam festival Ngani-ani yang setelah pandemik nanti akan diselenggarakan secara masal di desa Sabrang Kecamatan Delanggu.

\section{DAFTAR PUSTAKA}

Biro Pusat Statistik Kabupaten Klaten. (2018). Luas Panen, Produksi, dan Produktivitas Padi menurut Kecamatan ( $\mathrm{Ha})$, 2018. URL: https://klatenkab.bps.go.id/statictable/2015/09/17/149/luas-panen-ratarata- produksi-produksi-padi-sawah-dan-padi-gogo-menurut-kecamatan-dikabupaten- klaten-tahun-2014.html [Diakses pada 1 Oktober 2020]

Kondo, Y., Nagase, K., Sato, T., Enari, K. (2003). The Design of an Ecofish; A Handmade Graywater Purification Tool as a Circulation Type Resource. The Journal of the Asian Design International Conference, Vol. 1

Purwandaru, P., Wei, F.T., Ueda, A. (2019). The Rice Straw Organization in Japan: Preservation and Development Methods of Japanese Rice Straw Culture. Convash 2019, Surakarta.

Purwandaru, P., Wisesa, T.P., Darajat, T.M. (2018). The Indigenous-Led Regional Development in Delanggu and Juwiring Districts of Indonesia through the Design Approach of "Flowering of the Total Person". Idealogy journal special issue AICAD18, pp. 215-224.

Suzuki, N., Miyazaki, K. (2008). Flowering of the Total Person: A Practival Design Philosophy for Indigenous-Led Regional Development. Bulletin of JSSD, Vol. 55 No.1, pp.37-46.

Sujiono, B. (2007). Metode Pengembangan Fisik. Edisi Revisi. Jakarta: Universitas Terbuka.

Tabrani, P. (2012). Bahasa Rupa. Cetakan ke-3 dengan revisian. Proses Kreasi Apresiasi Belajar. Bandung: Kelir.

Ueda, A., Ooga, S. (2009). The Culture of "Mottainai" seen as Symbiosis Between Japan's Ceramic-Producing Regions and the Natural Environment. Bulletin of JSSD, Vol. 57 No.1, pp.65-74. 